\title{
An ASSESSMENT OF RECREATION IMPACTS In AlPINE AND SUBALPINE AREAS OF Grand Teton National Park: Preliminary FINDINGS
}

\section{Christopher MONZ $\downarrow$ ASHLEY D'ANTONIO UTAH STATE UNIVERSITY $\downarrow$ LOGAN}

\begin{abstract}
$\uparrow \quad$ ABSTRACT
Changes to resource conditions due to recreation use were examined in select locations in Grand Teton National Park. The study focused on assessing areas off designated trails and sites, where visitor use can often result in rapid and undesirable resource impacts. Preliminary results suggest that while resource change is significant in some locations, impacts tend to be limited spatially to areas surrounding popular destination sites. In addition, several alpine and subalpine locations of known recreation use showed little or no resource change outside of designated trails and sites. This work provides a baseline condition assessment that allows for an examination of change over time and an evaluation of the effectiveness of visitor management actions.
\end{abstract}

\section{$\uparrow \quad$ INTRODUCTION}

The demand for wildland recreation and nature-based tourism opportunities continues to increase in many protected areas in North America (Cordell 2008) and worldwide (De Lacy and Whitmore 2006). With this increased use has come human disturbance and change to the environmental conditions of protected areas, and an associated management effort directed at minimizing undesirable resource impact. Understanding resource condition trends through assessment and monitoring is essential for many aspects of sound adaptive management, particularly in determining the effectiveness of management actions in achieving resource protection goals.

Visitor activities in wildland areas inevitably have some consequences to environmental conditions. Even the most careful visitors to natural environments can potentially disturb soil, vegetation and wildlife. Fundamental management decisions as to the level of acceptable and appropriate disturbance to natural systems can be difficult and challenging and must be well informed.

Considerable research conducted over the last 40 years has demonstrated the relationships between visitor use and resource change. Recently, this information has been reviewed and summarized (Monz et al. 2010) and the new discipline of Recreation Ecology has evolved. Several fundamental principles can be generalized from this body of literature including:

- Recreation activities can directly affect the soil, vegetation, wildlife, water and air components of ecosystems.

- Other ecosystem attributes (i.e., structure, function, etc.) can be affected given the interrelationships between ecosystem components.

- For a given finite space, the relationship between change and use is generally curvilinear, with the majority of change occurring with initial use.

- Although some generalizations apply, resistance and resilience to visitor use disturbance is ecosystem specific. 
- The amount and distribution of use and visitor behavior are primary driving variables in determining the amount of resource change.

Given these principles, recreation ecology studies of two types are generally performed in wildland areas in an effort to assist managers in the avoidance and mitigation of visitor impacts. Experimental studies (e.g., Monz 2002, Cole and Monz 2002) examine causal relationships between use type and intensity and ecosystem-specific components. These studies employ carefully controlled experimental designs and can determine the levels of visitor use at which a given ecosystem (or ecosystem component) can tolerate. Monitoring and assessment studies (e.g., Marion and Leung 1997) are perhaps more common as managers often find them to be of considerable utility. These studies assess and monitor the location and extent of visitor use and resource impacts. Conducted over the long term, these studies provide an initial assessment of the current resource conditions, the trends of how impacts are changing over time, and an evaluation of the effectiveness of management actions.

Considerable literature also exists on the management of visitor resource impacts (e.g., Hammitt and Cole 1998, Manning 1999). The development of specific, accurate monitoring indicators is considered fundamental to the management process and moreover is an essential process in various management frameworks (Manning 1999). As such, recreation ecology studies are an integral component of framework approaches adopted by most land management agencies (e.g., Limits of Acceptable Change Planning Framework). Recreation ecology studies support these frameworks by contributing sound science to the process of developing monitoring indicators and in measuring indicators over time (National Park Service 1997).

The goal of this study was to apply a practical and efficient monitoring and assessment approach to select areas in Grand Teton National Park (GTNP) in order that future assessments would be capable of determining the trajectory of resource change. To accomplish this goal we selected sites with decision criteria based on their ecological, managerial, use-related and visitor destination characteristics and assessed these locations for visitor use-related resource change. We focused specifically on areas off of designated trails and sites where visitor use can lead to rapid and often undesirable resource changes.

\section{METHODS}

\section{Selection of Assessment Areas}

An area selection matrix was developed in consultation with the National Park Service staff (Table 1) that stratified locations by management zone, use level and alpine and subalpine ecosystem type. Once representative sites were determined based on the matrix, the study used three

Table 1. Location selection matrix for recreation resource assessment in Grand Teton National Park. Note: locations in highlighted in blue will be assessed in 2010 .

\begin{tabular}{|c|c|c|c|c|c|c|}
\hline \multirow{4}{*}{$\begin{array}{l}\text { Ecosystem } \\
\text { Type } \\
\text { Destination } \\
\text { Type- Lake }\end{array}$} & \multicolumn{6}{|c|}{ Grand Teton National Park Management Zones } \\
\hline & \multicolumn{2}{|c|}{ Zone II- Trail Corridors } & \multicolumn{2}{|c|}{ Zone III- Near Pristine } & \multicolumn{2}{|c|}{ Zone IV-Pristine } \\
\hline & $\underline{\text { Alpine }}$ & $\underline{\text { Subalpine }}$ & $\underline{\text { Alpine }}$ & $\underline{\text { Subalpine }}$ & $\underline{\text { Alpine }}$ & Subalpine \\
\hline & & & & & & \\
\hline Use Level Low & Holly Lake & $\begin{array}{l}\text { Bearpaw/ } \\
\text { Trapper Lakes }\end{array}$ & $\begin{array}{l}\text { Lake } \\
\text { Taminah }\end{array}$ & Delta Lake & $\begin{array}{l}\text { Rimrock } \\
\text { Lake }\end{array}$ & Mink Lake \\
\hline $\begin{array}{r}\text { Use Level } \\
\text { High }\end{array}$ & $\begin{array}{l}\text { Lake } \\
\text { Solitude }\end{array}$ & $\begin{array}{l}\text { Amphitheatre } \\
\text { and Taggart } \\
\text { Lakes }\end{array}$ & $\begin{array}{l}\text { Lake of the } \\
\text { Crags }\end{array}$ & $\begin{array}{l}\text { Arrowhead } \\
\text { Pond }\end{array}$ & NA & NA \\
\hline \multicolumn{7}{|l|}{$\begin{array}{l}\text { Destination } \\
\text { Type-Other }\end{array}$} \\
\hline Use Level Low & $\begin{array}{l}\text { Paintbrush } \\
\text { Divide }\end{array}$ & $\begin{array}{l}\text { Paintbrush } \\
\text { Canyon }\end{array}$ & $\begin{array}{l}\text { Upper } \\
\text { Avalanche } \\
\text { Canyon } \\
\text { Lower }\end{array}$ & $\begin{array}{l}\text { Avalanche } \\
\text { Canyon }\end{array}$ & $\begin{array}{l}\text { Moose } \\
\text { Basin } \\
\text { Divide }\end{array}$ & $\begin{array}{l}\text { Leigh } \\
\text { Canyon }\end{array}$ \\
\hline $\begin{array}{r}\text { Use Level } \\
\text { High } \\
\end{array}$ & $\begin{array}{l}\text { Cardiac } \\
\text { Ridge }\end{array}$ & $\begin{array}{l}\text { Lower Cascade } \\
\text { Canyon }\end{array}$ & $\begin{array}{l}\text { Saddle on } \\
\text { GT }\end{array}$ & Apex Trail & NA & NA \\
\hline
\end{tabular}


fundamental approaches: 1) mapping and assessment of observable areas of recreation disturbance, that is, visitor created trails and sites and 2) identification of large polygons of diffuse recreation disturbance and 3) within areas of diffuse recreation disturbance, a random sample of $1 \mathrm{~m}^{2} \mathrm{~s}$ where vegetation cover, species composition, bare ground and other parameters were assessed. These methodologies are based in standard recreation ecology techniques and have recently been employed in the assessment of recreation impacts in alpine mountain summit areas of the Northeast US (Monz et al. in press).

\section{Resource Condition Assessment}

Preliminary site visits revealed that selected areas exhibited typical disturbances found in park settings: linear and nodal areas of intensive trampling disturbance resulting from visitors hiking off formal (official) trails and sites to access climbing routes, vistas, or for exploration and other reasons. Managers reported that the proliferation of informal (visitorcreated) trails is a common problem that contributes substantial trampling impact to fragile vegetation and substrates. Observations also revealed that visitation frequently resulted in the trampling of substrates and vegetation in many gathering areas and vista sites. Assessing the conditions of these informal trails and sites is particularly important in alpine and subalpine ecosystems because of their limited spatial extent, fragility, and potential for permanent and irreversible vegetation and substrate loss.

To assess conditions on informal recreation sites we primarily relied on adapting recreation ecology assessment techniques developed for formal campsites (e.g., Marion, 1995). For each location, an assessment area was mapped and foot searches identified all recreation sites, defined as nodal areas of visually obvious substrate disturbance created by visitor use. The size of each site was assessed using the radial transect method (Marion, 1995); a permanent reference point was recorded with a Trimble ${ }^{\circledR}$ GeoXT GPS device and Hurricane antenna, and area calculations and GIS coordinates were provided by Excel spreadsheet calculations. All GPS data were post-processed using Trimble's Pathfinder Office to obtain the highest accuracy possible. Vegetation cover and soil exposure were evaluated onsite and in adjacent undisturbed controls as the mid-point value of six cover classes (Marion, 1995). Assessments of the number of trees and shrubs with damage, and root exposure, number of intersecting informal trails, and assessments of litter/trash also followed Marion (1995). Digital photos were taken to document impacts and aid in site relocation.

Assessing informal trails was more challenging in alpine areas because the terrain is often dominated by barren rock and informal trails are readily apparent only on soil substrates. Thus, informal trails in these environments are frequently discontinuous and short, increasing the difficulty of locating and documenting the trail fragments and evaluating their condition. While remote sensing techniques are possible, they require expensive highresolution imagery and complex analytical processing that place this option beyond the means of most land managers. Remote sensing is also challenging in subalpine areas due to the prevalence of well developed tree canopies.

For this study, we used a GPS based mapping and assessment procedure, as used in similar surveys such as Marion and Leung (1999) and Marion, Wimpey and Park (2009). We used the GeoXT GPS and careful foot-based searching within each study area to map the locations of all informal trail segments. Two informal trail condition attributes were assessed during field collection as described in Marion et al. (2009): condition class (CC) ratings on a 1-5 scale, and an assessment of average tread width (TW). A new informal trail segment was designated and assessed when a consistent change in condition class or width was noted in the field.

\section{Intensive Groundcover Assessment- Lower Saddle of the Grand Teton}

Intensive measurements were conducted on the Lower Saddle of the Grand Teton due the importance of this area from a visitor use and access perspective and due to the high use in a high alpine setting. In addition to applying the aforementioned site and visitor created trail assessments, we also employed a based, image analysis sampling technique (Booth et al. 2005) to measure vegetation and ground cover. This procedure involved three field components: 1) identification and mapping of an area of probable recreation use at the Lower Saddle; 2) creation of a stratified random-grid of sampling locations using ArcGIS 9.3 software; and 3) navigation to sample locations with the GPS and obtaining digital images of $1 \mathrm{~m}^{2}$ quadrats for subsequent image analysis of ground cover classes.

First the area of possible recreation use was mapped using the GPS, and a polygon was uploaded to ArcGIS (ESRI, Inc., Redlands, CA USA). Hawth's Analysis Tools extension for ArcGIS was used to 
create a random grid overlay on the polygon. Quadrat photos were taken with a Nikon COOLPIX P50 8.1megapixel digital camera mounted on a frame with a $1 \mathrm{~m}^{2}$ base that positioned the camera for nadir (overhead perspective) images $1.4 \mathrm{~m}$ above ground level. Measurements from digital images were used to quantify the relative cover of ground cover types using SamplePoint software (Booth, Cox, \& Berryman, 2006). Ten ground cover classes were included in the classification of the Lower Saddle including graminoids, shrubs, forbs, lichens, mosses organic soil, mineral soil, bedrock, and gravel.

\section{$\uparrow \quad$ RESUlTS \& DISCUSSION}

\section{Resource Conditions at Select Sites}

During the 2009 field season, a total of twelve of a possible twenty locations were successfully assessed for recreation-related disturbances to resource conditions (Table 1). The remaining eight locations will be assessed during the summer field season in 2010.

Initial results for the assessment work indicate a limited and localized development of visitor created trails and sites as illustrated in the examples provided (Figures 1 and 2). For example, at Trapper and Bearpaw Lake (Figure 1), numerous non-system trail segments were located, mapped and assessed for resource condition quality, but no visitor created sites were found.

At the Lower Saddle on the Grand Teton (Figure 2), all trail segments and sites were mapped and assessed within an area of likely recreation use. These findings illustrate the location and extent of recreation disturbances in these areas and provide important information for future monitoring of changes in the extent, location and intensity for recreation-related resource disturbance in these locations.

Examination of a summary of resource changes assessed across management zones and ecosystem types (Table 2) suggests some possible aspects for further investigation. First, the subalpine areas assessed have a high degree of resource change, with considerable trail and site formation across management zones II and III. Of the alpine areas assessed thus far, the Lower Saddle on the Grand Teton accounts for most of the resource change assessed (alpine zone III). This is understandable given the importance of this location to climbers and current impacts appear to be limited to approximately $1 \%$ of the total possible use area on the Saddle Quadrant-based sampling on the Lower Saddle provides a classification of groundcover in accord with general cover classes (Table 3). Future assessments using a similar approach can determine if overall changes are occurring, the degree of recreation disturbance and an identification of individual plant species, if desired. (Figure 2).

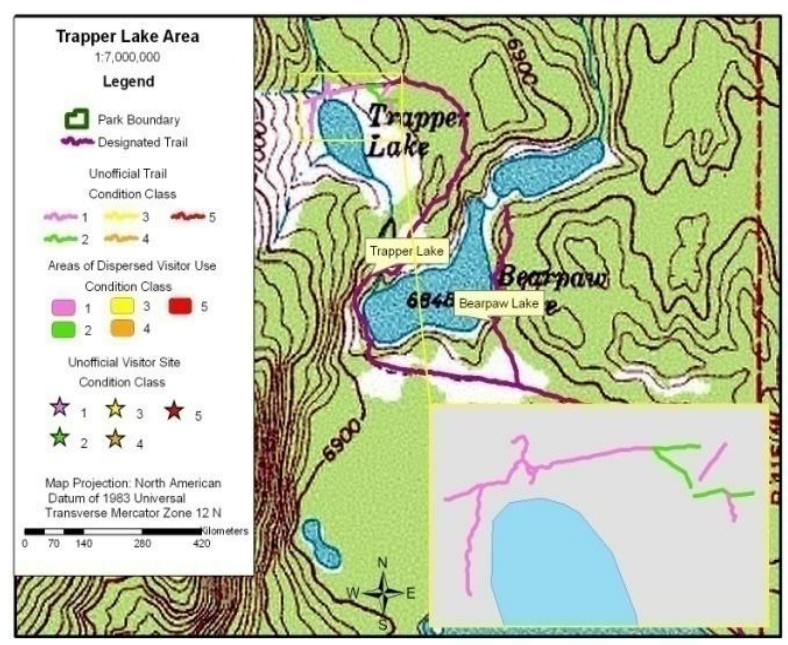

Figure 1. An example of visitor created trails in a subalpine location.

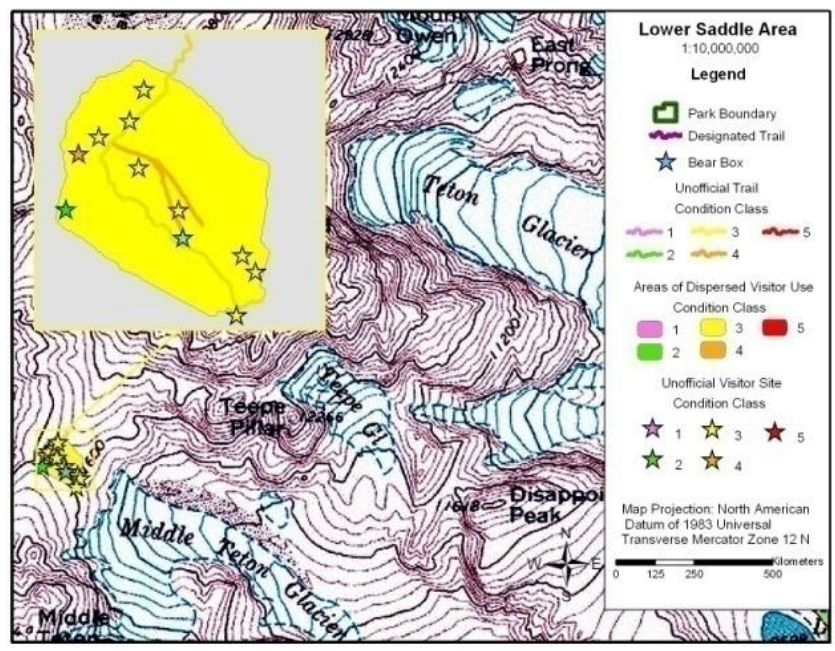

Figure 2. An example of visitor-created trails and sites in an alpine location 
Table 2. Preliminary findings of the extent and degree of recreation related disturbance at selected sites across management zones. Note: these data are preliminary do not represent a complete census of resource change in each zone.

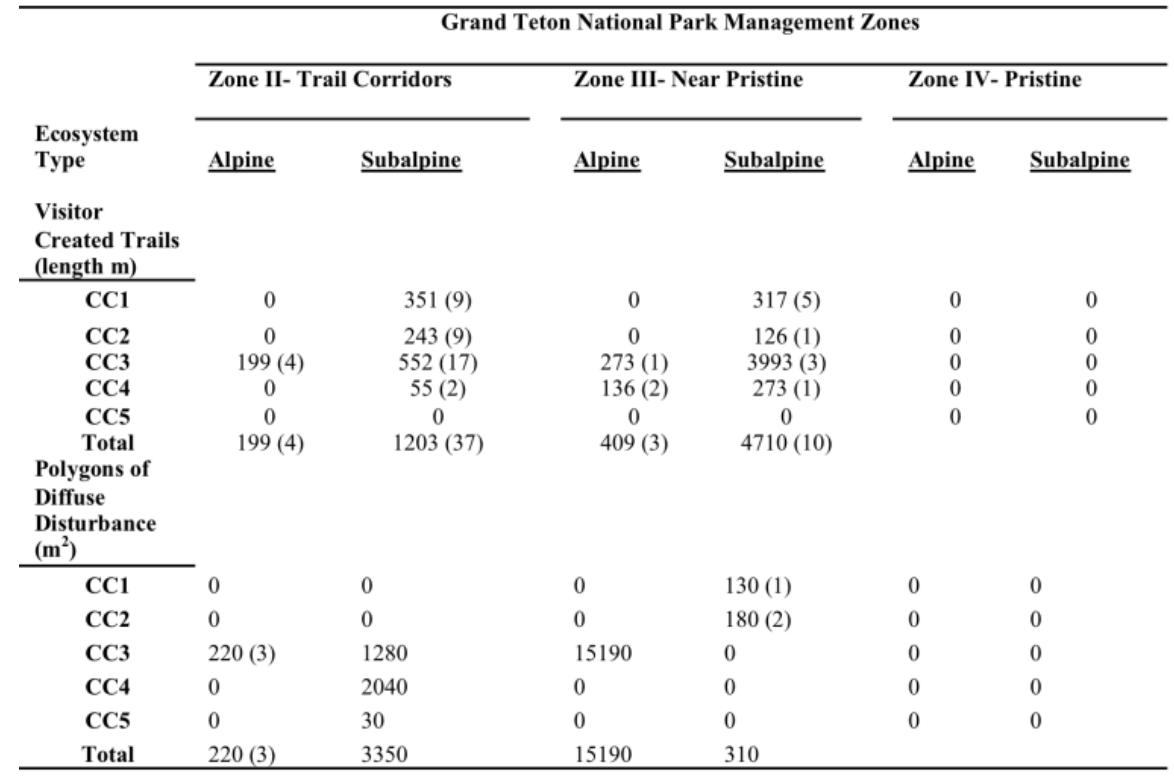

Table 3. Preliminary classification of groundcover on the Lower Saddle based on analysis of $1 \mathrm{~m}^{2} \mathrm{~s}$.

\begin{tabular}{ll}
\hline Groundcover Class & Cover (\%) \\
\hline Exposed Rock & 35.7 \\
Gravel & 19.2 \\
Sand & 1.1 \\
Exposed Soil & 15.0 \\
Mosses & 24.3 \\
Forbs & 0 \\
Shrubs & 0 \\
Grasses & 3.7 \\
\hline
\end{tabular}

\section{Implications and Future Research}

This work provides an important baseline for resource conditions to inform visitor management efforts in Grand Teton National Park. Assessment of current conditions allows managers to determine if actions are needed in specific locations to limit impacts. Future reassessment of these locations allows for a determination of the effectiveness of management actions as the trajectory of resource change can be determined.

This current work provides an initial glimpse into current resource conditions in GTNP. Ongoing work in 2010 will assess remaining sites and add locations as needed to complete a full suite of sites in accord with the site selection matrix.

\section{LITERATURE CITED}

Booth DT, Cox SE, Fifield C, Phillips M, Williamson N. 2005. Image Analysis Compared with Other Methods for Measuring Ground Cover. Arid Land Research and Management 19: 91-100.

Booth DT, Cox SE, Berryman RD. 2006. Point Sampling Digital Imagery with 'SamplePoint'. Environmental Monitoring and Assessment 123:97-108.

Cole DN, Monz CA. 2002 Trampling disturbance of subalpine vegetation, Wind River Mountains, Wyoming. Arctic, Antarctic and Alpine Research 34(4): 365-376.

Cordell HK. 2008. The latest on trends in naturebased outdoor recreation and tourism. Forest History Today Spring: 4-10

De Lacy T, Whitmore M. 2006. Tourism and recreation. In: Lockwood M, Worboys GL, Kothari A, editors. Managing protected areas: a global guide. London: Earthscan. P.497-527. 
Hammitt WE, Cole DN. 1998. Wildland recreation: ecology and management. $2^{\text {nd }}$ ed. New York: John Wiley.

Leung YF, Marion JL. 1999. The influence of sampling interval on the accuracy of trail impact assessment. Landscape and Urban Planning 43(4):167.

Manning RE. 1999. Studies in Outdoor Recreation. 2nd ed. Corvallis(OR): Oregon State University Press.

Marion JL. 1995. Capabilities and management utility of recreation impact monitoring programs. Environmental Management, 19: 763-771.

Marion JL, Leung Y. 1997 An assessment of campsite conditions in Great Smoky Mountains National Park. USDI National Park Service Research Resources Management Report.

Marion JL, Wimpey J, Park L. 2009. Monitoring protocols for characterizing trail conditions, understanding degradation, and selecting indicators and standards of quality, Acadia National Park, Mount Desert Island. Virginia Tech College of Natural Resources, Forestry/Recreation Resource Management, Blacksburg, VA.
Monz CA. 2002. The response of two arctic tundra plant communities to human trampling disturbance. Journal of Environmental Management 64:207-217.

Monz CA, Cole DN, Marion JL, Leung YF. 2010. Sustaining Visitor Use in Protected Areas: Future Opportunities in Recreation Ecology Research Based on the USA Experience. Environmental Management 45(3):551-562.

Monz CA, Marion JL, Goonan KA, Manning RE, Wimpey J, Carr C. (in press) Assessment and monitoring of recreation impacts and resource conditions on mountain summits: Examples from the Northern Forest, USA. Mountain Research and Development.

National Park Service. 1997. VERP: The visitor experience and resource protection framework- a handbook for planners and managers. Denver(CO): Denver Service Center. 